\title{
Matriz extracelular e enzimas degradatórias na hematopoese e doenças onco-hematológicas
}

\author{
Extracellular matrix in hematopoiesis and hematologic malignancies
}

Juliana L. Dreyfuss ${ }^{1}$

José S. R. Oliveira ${ }^{2}$

\begin{abstract}
A matriz extracelular (MEC) é uma rede complexa composta por quatro grandes classes de macromoléculas: colágenos, proteoglicanos (PGs), glicosaminoglicanos (GAGs) e glicoproteínas adesivas. As interações entre as células e a MEC são cruciais para determinar os padrões de comportamento celular, tais como crescimento, morte, diferenciação e motilidade. A hematopoese é o sistema responsável pela produção das células sangüineas. O controle da proliferação e diferenciação destas células é feito através da interação das células com o microambiente da medula óssea (matriz extracelular). A adesão de progenitores hematopoéticos a moléculas da MEC e a ativação das integrinas são modulados por uma variedade de citocinas e fatores de crescimento, e esta modulação parece ser o mecanismo de regulação que influencia a proliferação de células-tronco e progenitores hematopoéticos, migração transendotelial ou transestromal e homing. Tanto no processo de migração, homing e invasão tumoral, as células seguem os seguintes passos: 1-Degradação da MEC por enzimas secretadas pelas células: metaloproteinases, colagenases, plasmina, catepsinas, glicosidases e heparanases; 2 - Locomoção das células na região da MEC previamente degradada pelas enzimas; 3 - Adesão das células via receptores especificos da superficie celular, que geralmente interagem com componentes da MEC. Nas doenças onco-hematológicas, a interação das células neoplásicas com a matriz extracelular também influencia na agressividade e prognóstico da doença. Rev. Bras. Hematol. Hemoter. 2008;30(5):398-405.
\end{abstract}

Palavras-chave: Hematopoese; matriz extracelular; doenças onco-hematológicas.

\section{Introdução}

Estroma medular e moléculas da MEC da medula óssea

O estroma é constituído de osteoblastos, pré-osteoblastos, células endoteliais, adipócitos, células de tecido conjuntivo e MEC.

As células do microambiente medular possuem funções especificas, como a sinalização para o condicionamento, diferenciação e maturação celular, não sendo apenas um sistema de suporte físico. Estas células depositam no meio extracelular componentes como colágeno, fibronectina (FN), laminina (LN), trombospondina (TPS), hemonectina e ácido hialurônico $(\mathrm{AH}){ }^{1,2}$

Em culturas de células de medula óssea de longa permanência (LMTC), tais células formam camadas aderentes e heterogêneas, que promovem as condições de crescimento e diferenciação para células hematopoéticas in vitro. ${ }^{3}$ Sabe-se que as células do estroma produzem fatores solúveis e componentes da MEC que influenciam na diferenciação e proliferação hematopoética. ${ }^{4-7}$

A especificidade do microambiente pode ser demonstrada no transplante de medula óssea (TMO) em receptores irradiados. As células-tronco injetadas por via endovenosa,

\footnotetext{
Correspondência: Juliana Luporini Dreyfuss

Universidade Federal de São Paulo, Disciplina de Biologia Molecular

Rua Três de Maio, 100 - $4^{\circ}$ Andar - Vila Clementino

04044-020 - São Paulo-SP - Brasil

Tel: 5511 5576-4442; Fax: 5511 5573-6407

E-mail: jdreyfuss@gmail.com
}

${ }^{l}$ Farmacêutica Bioquímica. Pesquisadora da Universidade Federal de São Paulo (Unifesp) - São Paulo-SP.

${ }^{2}$ Professor Adjunto da Disciplina de Hematologia e Hemoterapia da Universidade Federal de São Paulo (Unifesp) - São Paulo-SP. 
migram para a medula óssea (MO), alojando-se e reconstituem a hematopoese. Este processo complexo envolve várias fases: identificação específica pelas células endoteliais, transmigração dentro dos espaços extra-sinusoidais e localização específica na MO. ${ }^{5}$

\section{Interações das células de MEC nas doenças onco-hematológicas}

A matriz extracelular (MEC) é uma rede complexa composta por quatro grandes classes de macromoléculas: colágenos, proteoglicanos (PGs), glicosaminoglicanos (GAGs) e glicoproteínas adesivas, ${ }^{8}$ que proporcionam um arcabouço físico para a sustentação da estrutura tecidual, determinando a hidratação e conseqüentemente o volume do tecido, criando espaços para o transporte de moléculas, organização dinâmica e resistência às forças de compressão.

As interações entre as células e a MEC são cruciais para determinar os padrões de comportamento celular, tais como crescimento, morte, diferenciação e motilidade que, por sua vez, apresentam importância em diversos mecanismos, como morfogênese, inflamação, resposta imune, invasão parasitária, transformação celular e metástase. ${ }^{9}$

A interação de células tumorais com a membrana basal e a MEC no processo de invasão tumoral pode ser dividida em três etapas: 1 - Degradação da MEC por enzimas secretadas pelas células tumorais: metaloproteinases, colagenases, plasmina, catepsinas, glicosidases e heparanases. Estas enzimas estão associadas com a invasão, pois levam à desorganização e à fragmentação dos componentes do estroma e da membrana basal; 2 - Adesão da célula tumoral via receptores específicos da superfície celular, que geralmente interagem com componentes da MEC; 3 - Locomoção da célula tumoral na região da MEC previamente degradada pelas enzimas. ${ }^{10-13}$

Interações anormais entre células hematopoéticas em desenvolvimento e seu microambiente podem, ao menos em parte, causar a saída prematura de blastos nas leucemias, mas ainda não está claro se um microambiente medular "leucêmico" existe. . $7,14-18^{-18}$

No mieloma múltiplo (MM) ainda não está completamente elucidado o mecanismo pelo qual estas células permanecem na medula óssea e qual o papel do microambiente medular. O melfalan e prednisona (MP), usados com sucesso no tratamento do MM, têm efeito no estroma da MO, possivelmente aumentando a adesão das células ao estroma pelo VCAM-1 e proteínas da MEC, a exemplo da FN e colágenos. Sabe-se que várias destas moléculas funcionam como mediadores celulares interagindo com outras células hematopoéticas durante a migração. O microambiente produz citocinas importantes para o crescimento das células mielomatosas como IL-6, IL-8 e GM-CSF. ${ }^{19}$

Terapeuticamente dispõem-se de vários protocolos, que utilizam citocinas para mobilizar as células-tronco e progenitoras para transplantes de medula óssea. $\mathrm{O}$ mecanismo molecular desta mobilização não está completamente entendido, mas certamente mudanças nas interações de adesão no microambiente devem ocorrer. ${ }^{5}$

\section{Componentes da MEC de medula óssea}

\section{Fibronectina $(F N)$}

É um importante membro da classe das glicoproteínas adesivas que desempenham um papel relevante em muitas interações entre células e outras moléculas da MEC. A FN pode ser encontrada na forma plasmática solúvel e também como FN celular ou tecidual, produzida por uma grande variedade de tipos celulares. ${ }^{20}$

A expressão de $\mathrm{FN}$ em diferentes sistemas in vivo e in vitro tem enfatizado seu papel em estimular a adesão, migração e diferenciação de inúmeros tipos celulares durante o desenvolvimento embrionário, nos processos de reparo tecidual onde as interações com integrinas exercem papel ímpar, na adesão de plaquetas à matriz danificada de colágeno, além de facilitar a migração e adesão de fagócitos e viabilizar a matriz para a proliferação celular. ${ }^{21}$

A FN é uma molécula imprescindível da MEC que media a adesão de várias linhagens de células hematopoéticas. $\mathrm{A}$ adesão à $\mathrm{FN}$ ou a ligação celular aos seus fragmentos estimulam a proliferação e migração de progenitores hematopoéticos, e a proliferação de progenitores comprometidos e células já diferenciadas. ${ }^{22,23}$

Células hematopoéticas $\mathrm{CD} 34^{+}$e CD $34^{+} \mathrm{CD} 38^{-}$aderem à $\mathrm{FN}$ em cultura. A adesão de progenitores hematopoéticos à $\mathrm{FN}$ e a ativação das integrinas são moduladas por uma variedade de citocinas e quimoquinas, e esta modulação parece ser o mecanismo de regulação mais importante que influencia a proliferação de células-tronco e progenitores hematopoéticos, migração transendotelial ou transestromal e homing. $22,24,25$.

\section{Laminina $(L N)$}

A LN pertence à família das macromoléculas multifuncionais presentes na membrana basal, são as proteínas não-colagênicas mais abundantes na MEC. ${ }^{26} \mathrm{As}$ LNs promovem o crescimento celular, migração, crescimento do tumor, metástase, regeneração de nervos, cicatrização, diferenciação e proliferação celular. A LN é uma das primeiras moléculas da MEC que aparece em mamíferos, no início do desenvolvimento, em um estágio em que o embrião possui 4-8 células. A estrutura molecular da LN é heterotrimérica, contendo três cadeias: $\alpha, \beta$ e $\gamma$, que assumem a forma de uma cruz assimétrica. . $^{21,27,28,29}$

Na medula óssea, a LN está presente nos cordões medulares, parede de arteríolas, na membrana basal de células endoteliais do sinusóide medular e adipócitos. Siler $e t a^{30}$ demonstraram que várias isoformas de LN estão presentes na medula óssea humana. As isoformas mais abundantes são as 8/9 e 10/11; esta última isoforma possui grande inte- 
ração adesiva com células $\mathrm{CD} 34^{+}$e apresentaram atividade mitogênica para células progenitoras hematopoéticas.

As células CD $34^{+}$e CD34+ CD38- têm capacidade de aderir em LNs 10/11 e acontece de forma muito similar à adesão à FN. Ainda as isoformas de LNs 10/11 promovem a migração de células $\mathrm{CD} 34^{+}$in vitro. ${ }^{25}$

Granulócitos maduros, linfócitos, macrófagos ativados, eosinófilos aderem em LNs extraídas de tumor de EHS (Engelberth-Holm-Swarn) ou isoladas de placenta. ${ }^{31-33}$ Essa adesão influencia tanto na sobrevivência quanto na maturação destas células.

As células aderentes à $\mathrm{LN}$ afetam a migração dos progenitores hematopoéticos, o que sugere uma função fisiológica para a LN durante a hematopoese. ${ }^{25}$

\section{Trombospondina (TPS)}

A TPS é uma glicoproteína grande (180kDa), trimérica e é sintetizada e secretada por uma ampla variedade de células, incluindo plaquetas, fibroblastos, células de músculo liso, células endoteliais, células da glia, queratinócitos e megacariócitos. ${ }^{34,35} \mathrm{~A}$ TPS é secretada por estas células e incorporada na MEC. Em LMTC, a TPS intracelular está presente em megacariócitos, células mononucleares e células fibroblato-like. ${ }^{36} \mathrm{~A}$ TPS está envolvida na adesão e interação celular com outros componentes extracelulares como os PGs e o fibrinogênio, ${ }^{37,38}$ crescimento celular e invasividade tumoral. ${ }^{39}$

A TPS está presente na medula óssea e tem um papel importante como molécula citoadesiva, envolvendo-se no processo de proliferação e diferenciação hematopoética. As células progenitoras humanas pluripotentes (CFU-GEMM) e progenitores condicionados (BFU-E,CFU-GM) se ligam à TPS, porém, durante a diferenciação e a maturação dos granulócitos, observa-se diminuição desta adesão. As células eritróides maduras perdem a capacidade de usar a TBS como molécula de adesão, mas esta capacidade é mantida pelos neutrófilos maduros. As células não aderentes produzem e secretam TPS, e em células leucêmicas uma adesão diferencial à TPS foi descrita. ${ }^{36}$

Long $e{ }^{a} l^{40}$ mostraram que a TPS, em combinação com a citocina SCF (stem cell factor), age sinergicamente com células progenitoras adesivas, dando sustentação durante a formação das colônias. Estes dados sugerem que uma determinada citocina, em conjunto com outros componentes da MEC, pode agir como um complexo de sinalização comum para o desenvolvimento dos progenitores.

\section{Glicosaminosglicanos (GAGs)}

GAGs são heteropolissacarídeos lineares constituídos por unidades dissacarídicas repetitivas. Estas unidades dissacarídicas são formadas alternadamente por uma hexosamina $(\alpha-\mathrm{D}$-glucosamina, $\beta$-D-glucosamina ou $\beta$-Dgalactosamina) e um açúcar não nitrogenado, que pode ser um ácido urônico (ácido $\beta$-D-glucurônico ou $\alpha$-L-idurônico) ou um açúcar neutro ( $\beta$-D-galactose), unidos por ligações glicosídicas, e são eles: condroitim 4 e 6 sulfato, dermatam sulfato, heparam sulfato, heparina, queratam sulfato e ácido hialurônico. ${ }^{41}$

Com exceção ao ácido hialurônico, os glicosaminoglicanos não ocorrem de forma livre nos tecidos, eles aparecem ligados a um core protéico, essas moléculas são chamadas de proteoglicanos (PG). ${ }^{42}$

Os PGs estão presentes em grandes quantidades na MEC (versicam e agrecam) e na superfície celular (glipicam e sindecam) e estão envolvidos em processos celulares fundamentais, como a proliferação, angiogênese, morfogênese e diferenciação celular. ${ }^{43-45}$

Com exceção do queratam sulfato, todos os demais GAGs são encontrados no microambiente hematopoético. ${ }^{46,47}$ Estes PGs são produzidos pelas células estromais e hematopoéticas e uma de suas funções mais importantes, é a ligação e apresentação das citocinas. Gordon et $a l^{48}$ mostraram que os PGs isolados da MO foram capazes de promover ligações exógenas com GM-CSF. Roberts $e t a l^{49}$ identificaram heperans sulfatos como componentes responsáveis pela ligação do GM-CSF à interleucina-3 (IL-3) e demonstraram sua forma ativa em células hematopoéticas. Entre os GAGs, a heparina e o HS se destacam na sua capacidade de interagir com grande gama de proteínas. A heparina e o HS regulam uma grande variedade de processos biológicos, incluindo hemostasia, inflamação, angiogênese, crescimento e adesão celular, entre outros. ${ }^{50,51}$

O ácido hialurônico tem também um papel particularmente importante no microambiente celular do câncer. Células tumorais exibem diversos receptores para este GAG, como CD44 e RHAMM (molécula de reconhecimento ao $\mathrm{AH}$ nos processos de migração-específica em vários tipos celulares), e sua adesão pode influenciar na mobilidade celular. $^{52} \mathrm{Na}$ maioria dos casos, a subseqüente diferenciação parece estar associada com a diminuição de AH. De modo geral, nestes exemplos, quando o movimento celular pára e inicia-se a adesão celular, há uma queda na quantidade de $\mathrm{AH}$, uma flagrante diminuição de receptores celulares para esta molécula, bem como um aumento na produção da enzima hialuronidase..$^{53}$

A expressão de RHAMM está aumentada em fibroblastos transformados com Ras, células B malignas e células que estão respondendo a algum tipo de injúria,${ }^{54} \mathrm{o}$ que parece aumentar a motilidade celular, pois, quando se tratam essas células com anticorpos anti-RHAMM, o processo é inibido. ${ }^{55}$

$\mathrm{O}$ AH e seu receptor RHAMM estão relacionados com a mobilização e tráfego de células hematopoéticas. A motilidade de células $B$ e células leucêmicas em mieloma múltiplo parece ser dependente de $\mathrm{AH}$, pois este GAG promove a migração de células $\mathrm{B}$ de pacientes com mieloma múltiplo, o que não acontece com outras moléculas da MEC, como colágeno tipo I, colágeno tipo IV e LN. A maioria das células 
$\mathrm{B}$ de sangue periférico destes pacientes liga $\mathrm{AH}$, enquanto células $B$ de medula óssea não. Essa ligação das células de SP é inibida pela incubação com anticorpos anti-CD44. RHAMM parece ser ativo na ligação de $\mathrm{AH}$, na deformação celular e motilidade, enquanto CD44 é ativo na ligação de $\mathrm{AH}$ nas células circulantes e inativo nas células de medula óssea; assim, a migração de células de mieloma de SP é inibida por anti-RHAMM e não é inibida por anti-CD44, o que indica que é o RHAMM e não o CD44 que media a motilidade celular sobre AH. ${ }^{56}$

A interação AH-CD44 ativa a sinalização celular em linhagens celulares de linfomas e macrófagos, além de aumentar a proliferação celular durante a eosinopoese. ${ }^{57,58}$

O CD44 parece também mediar a adesão de células progenitoras hematopoéticas (CPHs) sobre o $\mathrm{AH}$. Dados em cultura de $\mathrm{CPHs}$ mostram que células CD34+ que expressam fortemente o CD44 aderem bastante ao $\mathrm{AH}$, e esta adesão ainda é aumentada pelo tratamento destas células com o éster de forbol PMA, SCF, GM-CSF e interleucina 3. A adesão ao $\mathrm{AH}$ via CD44 ocorre em células progenitoras grânulomonocíticas e eritróides, como também em células mais imaturas, como progenitores pré-CFU. ${ }^{59}$

Níveis séricos elevados de $\mathrm{AH}$ ocorrem em determinados processos patológicos, tais como tumores malignos, ${ }^{60}$ cirrose hepática, ${ }^{61}$ artrite reumatóide, sendo considerado um possível marcador desses processos. Níveis urinários elevados de AH caracterizam pacientes com nefroblastoma (tumor de Wilms), sendo este utilizado como marcador de seguimento, uma vez que, com a remoção do tumor, o composto desaparece da urina. ${ }^{62} \mathrm{O}$ teor de $\mathrm{AH}$ no soro de indivíduos com oftalmopatia de Graves pode discriminar pacientes com doença em atividade ou não. ${ }^{63,64} \mathrm{Um}$ aspecto importante no processo da progressão tumoral é a angiogênese. Por exemplo, $\mathrm{AH}$ e, mais especificamente, os seus fragmentos são fatores angiogênicos. ${ }^{65}$

\section{Enzimas degradatórias da MEC}

\section{Heparanase}

A HPA (HPA) é uma endo-beta-glucuronidase que quebra ligações glicosídicas intrassacarídicas do Heparam Sulfato (HS) entre a hexosamina (glucosamina-N-acetilada) e o ácido D-glucurônico. ${ }^{66-72}$ Existem três formas de "splicing alternativo" que transcrevem três diferentes mRNA que codificam proteínas de 480, 534 e 592 aminoácidos para diferentes isoformas de HPA (HPA1, HPA2 e HPA3). Os três isômeros são proteínas intracelulares associadas à membrana. A HPA é expressa em células normais, como células endoteliais, queratinócitos, plaquetas, mastócitos, neutrófilos, macrófagos, linfócitos T e B e nos tumores malignos, como linfomas, melanoma e carcinomas..$^{72}$ Estudos comparativos demonstraram que a HPA1 é altamente expressa em linfonodos e placenta, é pouco expressa em outros tecidos, enquanto a HPA2 é altamente presente em cérebro, glându- la mamária, próstata, intestino delgado, testículo e útero, sendo pouco expressa em placenta e linfonodos.

O mecanismo pelo qual a HPA se relaciona com o câncer é a formação de oligossacarídeos com atividade biológica resultante da degradação das cadeias de heparam sulfatos (HSs) que estão envolvidas com intensificação da proliferação e diferenciação celular e angiogênese. ${ }^{73} \mathrm{~A}$ HPA degrada os sindecans da superfície celular e os perlecans de membrana basal. ${ }^{74}$ Especificamente, o sidecam-1 presente na superfície das células epiteliais dos mamíferos tem sua relação com o desenvolvimento tumoral na dependência de sua degradação pela HPA. ${ }^{75}$ Acredita-se que o papel biológico dessa enzima Acredita-se que o papel biológico dessa enzima seja facilitar a invasão de células tumorais através da degradação da membrana basal vascular e da MEC pela HPA sintetizada pelas células tumorais ${ }^{76}$ Pode também liberar e ativar fatores de crescimento. Foi demonstrado que os fragmentos de HS resultantes da ação da HPA são capazes de ligar com maior afinidade ao FGF-2 (fator de crescimento básico de fibroblastos), ${ }^{77-79} \mathrm{e}$ estes fragmentos podem promover a invasão de células endoteliais, ou seja, angiogênese, ao ativarem fatores angiogênicos específicos. ${ }^{80,81}$

AHPA foi identificada em células hematopoéticas como plaquetas e neutrófilos ${ }^{82}$ e megacariócitos. ${ }^{81}$ Sua expressão está associada com alguns tipos específicos de desordens hematológicas, como em células mielóides da LMA, onde foi detectada no citoplasma, sendo, entretanto, limitada na membrana celular assim como na forma de mRNA em leucócitos de sangue periférico ${ }^{83} \mathrm{~A}$ HPA não foi observada em células-tronco hematopoéticas CD34+ e de processos linfoproliferativos. A expressão da HPA se associa com a diferenciação mielóide normal, alcançando sua máxima intensidade nas células mielóides maduras. ${ }^{84}$ É também expressa em monócitos normais sem distinção nítida quando comparada com células de LMA..$^{83}$ Há, entretanto, perda de expressão em células de LMC.

Sua atividade enzimática foi detectada em medula óssea de pacientes com mieloma múltiplo, porém foi negativa no plasma. Este aumento se relacionou com a agressividade tumoral e com a densidade microvascular. ${ }^{85} \mathrm{O}$ sindecam-1, que na forma solúvel no plasma promove crescimento tumoral, mostrou-se presente nestes pacientes com nítida relação de sua intensidade com a agressividade e progressão da doença. ${ }^{86-88}$

Recentemente foi observado que células do microambiente medular do mieloma múltiplo expressam a HPA na forma protéica e de mRNA. A HPA parece estar intimamente relacionada com a expressão e shedding do sindecam-1, já que linhagens celulares de mieloma múltiplo nocauteadas para o seu RNAi apresentam marcada redução do sindecam-1. Conclui-se que a HPA é um determinante crítico para a disseminação do mieloma e a intensidade de sua expressão é empregada como marcador de prognóstico. ${ }^{89,90}$ 
Diante dos dados descritos pode-se dizer que a HPAé uma enzima que se presta não apenas como um marcador tumoral, mas também de fator de prognóstico de metástases. ${ }^{72,81,91,92}$ Daí, sua caracterização merece estudos detalhados tanto para auxiliar no diagnóstico como ajudar na terapêutica dos tumores, através da criação de drogas antiHPA. ${ }^{93}$

\section{Catepsina B}

A catepsina B (CatB) é uma cisteíno-peptidase da família papaína que possui tanto atividade endopeptidásica quanto atividade carboxidipepetidil-peptidásica, ${ }^{94,95}$ degradando colágenos e proteoglicanos (PGs) em pH ácido; laminina, fibronectina e colágeno do tipo IV em $\mathrm{pH}$ ácido e neutro. ${ }^{96} \mathrm{~A}$ CatB é secretada na forma precursora inativa por células normais e em forma inativa ou madura e ativa por células tumorais. ${ }^{97,98}$

Os glicosaminosglicanos (GAGs) heparan sulfatos (HS) e heparina podem modular a atividade de algumas serinopeptidases e de seus inibidores naturais. ${ }^{99,100}$ A atividade da CatB é afetada pela presença de GAGs. ${ }^{101} \mathrm{O}$ HS da superfície celular ancora a $\mathrm{CatB}$ formando complexo que afeta a atividade enzimática aumentando em cinco vezes sua meia-vida em $\mathrm{pH}$ fisiológico. ${ }^{101}$

Em células normais ou tumorais, a CatB localiza-se nos lisossomos, está associada à membrana plasmática ou pode ser secretada. ${ }^{97,102,103}$ Entretanto, em células normais, a CatB foi também encontrada em vesículas perinucleares, enquanto nas células tumorais maior quantidade é secretada ou associada à membrana plasmática. ${ }^{104}$

A CatB participa da invasão tumoral através de degradação de componentes da MEC intracelularmente por atividade heterofagosomal das células tumorais ${ }^{96,105}$ ou extracelularmente pela ação direta associada à superfície celular na degradação da MEC. ${ }^{106}$

A CatB participa de uma cascata proteolítica metastática, na qual uma ou mais classes de peptidases participam, incluindo metalo-peptidases, serino-peptidases, cisteíno-peptidases, além de fatores como plasminogênio e plasmina. ${ }^{107}$ Esta cascata resulta em dissolução focal de proteínas de MEC e permite a invasão da célula tumoral. ${ }^{102} \mathrm{~A}$ CatB exerce função na oncogênese possivelmente como executora de apoptose, após sua liberação dos lisossomos e conseqüente ativação das vias clássicas desta provavelmente ao clivar membros da família pró-apoptótica Bcl-2. ${ }^{108} \mathrm{ACatB}$ é mediadora da invasão tumoral e é expressa nos seguintes tumores: carcinoma de bexiga, ${ }^{109}$ cólon e estômago, ${ }^{110}$ e pulmão. ${ }^{111} \mathrm{~A}$ intensidade de marcação da CatB, colágeno tipo IV ou LN foi inversamente proporcional entre si.

A CatB mostrou ser marcador de histiócitos no tecido linfóide e não foi encontrada em granulócitos maduros. ${ }^{112} \mathrm{Os}$ linfomas histiocíticos apresentam-se altamente positivos a CatB. ${ }^{12}$ Uma maior atividade desta enzima em células leucêmicas L1210 está relacionada com a capacidade de infiltra- ção hepática. ${ }^{113}$ Em cultura de células leucêmicas (linhagem K562), a CatB age como um mediador de morte celular. Barbosa et al ${ }^{114}$ mostraram que um composto paladaciclo ferroceno (BPC) tem atividade antileucêmica por induzir apoptose pela liberação lisossomal da CatB.

A diferenciação celular também parece ser regulada pela atividade da CatB. Na eritroleucemia murina há translocação da fração microssomal (pro-enzima) para a fração lisossomal (enzima ativa) de células que foram induzidas à diferenciação sugerindo que a CatB tem papel importante na degradação de proteínas que induzem diferenciação celular. ${ }^{115}$ Quando células promonocíticas U937 são tratadas com GM-CSF, observa-se um aumento nos níveis da CatB, que parece novamente estar relacionada com diferenciação celular. ${ }^{116} \mathrm{~A}$ atividade desta enzima está presente em célulasT leucêmicas de estágios iniciais da diferenciação tímica, e esta atividade cai cerca de dez vezes em células com fenótipos maduros. ${ }^{117}$

\section{Abstract}

The extracellular matrix (ECM) is a complex structure composed of collagens, proteoglycans, glycosaminoglycans and adhesive glycoproteins. Interactions between the cells and the ECM are crucial to determine cell behavior, such as growth, death, differentiation and motility. Hematopoiesis is the system responsible for the production of blood cells. The control of proliferation and differentiation of these cells is attained through the interaction of the cells with the bone marrow microenvironment. The adhesion of hematopoietic progenitors to ECM molecules and the integrin activation are modulated by a variety of cytokines and growth factors, and this modulation seems to be the mechanism of regulation that influences proliferation of hematopoietic cells, transendothelial/transstromal migration and homing. Both in the migration and homing process, and in tumoral invasion the cells undergo the following steps: 1 - Degradation of the ECM by enzymes, including metalloproteinase, collagenase, plasmin, cathepsin, glycosidase and heparanase, secreted by the cells; 2 - Cell migration through the region previously degraded by enzymes; and 3 - Cell adhesion to specific receptors located on the cellular surface, that generally interact with ECM components. In onco-hematologic diseases, the interaction of neoplastic cells with the extracellular matrix also influences aggressiveness and prognosis of the disease. Rev. Bras. Hematol. Hemoter. 2008; 30(5):398-405.

Key words: Hematopoiesis; extracellular matrix; onco-hematologic diseases.

\section{Referências Bibliográficas}

1. Keating A, Gordon MY. Hierarchical organization of hematopoietic microenvironments: role of proteoglycans. Leukemia. 1988;2 (11):766-9.

2. Bentley SA, Kirby SL, Anklesaria P, Greenberger JS. Bone marrow stromal proteoglycan heterogeneity: phenotypic variability between cell lines and the effects of glucocorticoid. J Cell Physiol. $1988 ; 136(1): 182-7$. 
3. Metcalf D, Willson TA, Hilton DJ, Di Rago L, Mifsud S. Production of hematopoietic regulatory factors in cultures of adult and fetal mouse organs: measurement by specific bioassays. Leukemia. 1995;9(9):1556-64

4. Bristow J, Tee MK, Gitelman SE, Mellon SH, Miller WL. Tenascin$\mathrm{X}$ : a novel extracellular matrix protein encoded by the human $\mathrm{XB}$ gene overlapping P450c21B. J Cell Biol. 1993;122(1):265-78.

5. Klein G. The extracellular matrix of the hematopoietic microenvironment. Experientia. 1995;51(9-10):914-26.

6. Greenberger J, Leif J, Crawford D, et al. Humoral and cell surface interactions during gamma-irradiation leukemogenesis in vitro. Exp Hematol. 1992;20(1):92-102

7. Liesveld JL, Winslow JM, Frediani KE, Ryan DH, Abboud CN. Expression of integrins and examination of their adhesive function in normal and leukemic hematopoietic cells. Blood. 1993;81 (1):112-21

8. Hay ED. Biogenesis and organization of extracellular matrix. FASEB J. 1999;13 Suppl 2:S281-3.

9. Chammas R, Veiga SS, Brentani RR. Glycobiology of lamininintegrin interaction and the metastatic phenotype. Mem Inst Oswaldo Cruz. 1991;86 Suppl 3:29-35.

10. Herszényi L, Plebani M, Carraro P, et al. Proteases in gastrointestinal neoplastic diseases. Clin Chim Acta. 2000; 291 (2): $171-87$

11. Liotta LA, Goldfarb RH, Terranova VP. Cleavage of laminin by thrombin and plasmin: alpha thrombin selectively cleaves the beta chain of laminin. Thromb Res. 1981;21(6):663-73.

12. Bernfield M, Götte M, Park PW, et al. Functions of cell surface heparan sulfate proteoglycans. Annu Rev Biochem. 1999; 68: 729-77.

13. Bernfield M, Hooper KC. Possible regulation of FGF activity by syndecan, an integral membrane heparan sulfate proteoglycan. Ann N Y Acad Sci. 1991;638:182-94.

14. Liesveld JL, Dipersio JF, Abboud CN. Integrins and adhesive receptors in normal and leukemic CD34+ progenitor cells: potential regulatory checkpoints for cellular traffic. Leuk Lymphoma. 1994;14(1-2):19-28.

15. Reuss-Borst MA, Bühring HJ, Klein G, Müller CA. Adhesion molecules on CD34+ hematopoietic cells in normal human bone marrow and leukemia. Ann Hematol. 1992;65(4):169-74.

16. Reuss-Borst MA, Klein G, Waller HD, Müller CA. Differential expression of adhesion molecules in acute leukemia. Leukemia. 1995;9(5):869-74

17. Teixidó J, Hemler ME, Greenberger JS, Anklesaria P. Role of beta 1 and beta 2 integrins in the adhesion of human CD34hi stem cells to bone marrow stroma. J Clin Invest. 1992;90(2):358-67.

18. Diamond MS, Springer TA. The dynamic regulation of integrin adhesiveness. Curr Biol. 1994;4(6):506-17.

19. Cheung JY, Miller BA. Molecular mechanisms of erythropoietin signaling. Nephron. 2001;87(3):215-22.

20. Humphries MJ, Obara M, Olden K, Yamada KM. Role of fibronectin in adhesion, migration, and metastasis. Cancer Invest. 1989; 7(4):373-93

21. Yamada KM. Adhesive recognition sequences. J Biol Chem. 1991;266(20):12809-12

22. Schofield KP, Humphries MJ, de Wynter E, Testa N, Gallagher JT. The effect of alpha4 betal-integrin binding sequences of fibronectin on growth of cells from human hematopoietic progenitors. Blood. 1998;91(9):3230-8.

23. Nojima Y, Humphries MJ, Mould AP, et al. VLA-4 mediates CD3dependent CD4+ T cell activation via the CS1 alternatively spliced domain of fibronectin. J Exp Med. 1990; 172(4):1185-92.
24. Peled A, Kollet O, Ponomaryov T, et al. The chemokine SDF-1 activates the integrins LFA-1, VLA-4, and VLA-5 on immature human $\mathrm{CD} 34(+)$ cells: role in transendothelial/stromal migration and engraftment of NOD/SCID mice. Blood. 2000;95(11):3289-96.

25. Gu YC, Kortesmaa J, Tryggvason K, et al. Laminin isoformspecific promotion of adhesion and migration of human bone marrow progenitor cells. Blood. 2003;101(3):877-85.

26. Aumailley M, Gayraud B. Structure and biological activity of the extracellular matrix. J Mol Med. 1998;76(3-4):253-65.

27. Engel J, Odermatt E, Engel A, et al. Shapes, domain organizations and flexibility of laminin and fibronectin, two multifunctional proteins of the extracellular matrix. J Mol Biol. 1981;150(1): 97-120.

28. Yurchenco PD, O'Rear JJ. Basement membrane assembly. Methods Enzymol. 1994;245:489-518.

29. Malinda KM, Kleinman HK. The laminins. Int J Biochem Cell Biol. 1996;28(9):957-9.

30. Siler U, Seiffert M, Puch S, et al. Characterization and functional analysis of laminin isoforms in human bone marrow. Blood. 2000; 96(13):4194-203.

31. Gu Y, Sorokin L, Durbeej M, Hjalt T, Jönsson JI, Ekblom M. Characterization of bone marrow laminins and identification of alpha5-containing laminins as adhesive proteins for multipotent hematopoietic FDCP-Mix cells. Blood. 1999;93(8):2533-42.

32. Giancotti FG, Comoglio PM, Tarone G. Fibronectin-plasma membrane interaction in the adhesion of hemopoietic cells. J Cell Biol. 1986;103(2):429-37.

33. Ekblom P. Receptors for laminins during epithelial morphogenesis. Curr Opin Cell Biol. 1996;8(5):700-6.

34. Baenziger NL, Brodie GN, Majerus PW. A thrombin-sensitive protein of human platelet membranes. Proc Natl Acad Sci USA. $1971 ; 68(1): 240-3$

35. Frazier WA, Dixit VM, Galvin NJ, Rotwein PR. Structure of human thrombospondin: complete amino acid sequence derived from cDNA. Semin Thromb Hemost. 1987;13(3):255-60.

36. Long MW, Dixit VM. Thrombospondin functions as a cytoadhesion molecule for human hematopoietic progenitor cells. Blood. 1990;75(12):2311-8

37. Bornstein P. Thrombospondins: structure and regulation of expression. Faseb J. 1992;6(14):3290-9.

38. Lawler J, Hynes RO. Structural organization of the thrombospondin molecule. Semin Thromb Hemost. 1987;13(3):245-54.

39. Riser BL, Varani J, O'Rourke K, Dixit VM. Thrombospondin binding by human squamous carcinoma and melanoma cells: relationship to biological activity. Exp Cell Res. 1988;174(2):319-29.

40. Long MW, Briddell R, Walter AW, Bruno E, Hoffman R. Human hematopoietic stem cell adherence to cytokines and matrix molecules. J Clin Invest. 1992;90(1):251-5.

41. Vynios DH, Karamanos NK, Tsiganos CP. Advances in analysis of glycosaminoglycans: its application for the assessment of physiological and pathological states of connective tissues. J Chromatogr B Analyt Technol Biomed Life Sci. 2002;781(12):21-38.

42. Wegrowski Y, Maquart FX. Involvement of stromal proteoglycans in tumour progression. Crit Rev Oncol Hematol. 2004;49(3): 259-68.

43. Hascall VC, Calabro A, Midura RJ, Yanagishita M. Isolation and characterization of proteoglycans. Methods Enzymol. 1994;230: 390-417.

44. Lindahl U, Höök M. Glycosaminoglycans and their binding to biological macromolecules. Annu Rev Biochem. 1978; $47: 385-417$. 
45. Chiarugi VP, Vannucchi S. Surface heparan sulphate as a control element in eukariotic cells: a working model. J Theor Biol. 1976 Sep 21;61(2):459-75.

46. Kjellén L, Lindahl U. Proteoglycans: structures and interactions. Annu Rev Biochem. 1991;60:443-75.

47. Kolset SO, Gallagher JT. Proteoglycans in haemopoietic cells. Biochim Biophys Acta. 1990;1032(2-3):191-211.

48. Gordon MY, Riley GP, Watt SM, Greaves MF. Compartmentalization of a haematopoietic growth factor (GM-CSF) by glycosaminoglycans in the bone marrow microenvironment. Nature. 1987;326 (6111):403-5

49. Roberts R, Gallagher J, Spooncer E, Allen TD, Bloomfield F, Dexter TM. Heparan sulphate bound growth factors: a mechanism for stromal cell mediated haemopoiesiss. Nature. 1988;3 32 (6162): 376-8.

50. Gambarini AG, Miyamoto CA, Lima GA, Nader HB, Dietrich CP. Mitogenic activity of acidic fibroblast growth factor is enhanced by highly sulfated oligosaccharides derived from heparin and heparan sulfate. Mol Cell Biochem. 1993;124(2):121-9.

51. Porcionatto MA, Nader HB, Dietrich CP. Heparan sulfate and cell division. Braz J Med Biol Res. 1999;32(5):539-44.

52. Delpech B, Girard N, Bertrand P, Courel MN, Chauzy C, Delpech A. Hyaluronan: fundamental principles and applications in cancer J Intern Med. 1997;242:41-8.

53. Sampaio LO, Dietrich CP. Changes of sulfated mucopolysaccharides and mucopolysaccharidases during fetal development. J Biol Chem. 1981;256(17):9205-10.

54. Pilarski LM, Masellis-Smith A, Belch AR, Yang B, Savani RC, Turley EA. RHAMM, a receptor for hyaluronan-mediated motility, on normal human lymphocytes, thymocytes and malignant B cells: a mediator in B cell malignancy? Leuk Lymphoma. 1994;14(5-6):363-74.

55. Hardwick C, Hoare K, Owens R, et al. Molecular cloning of a novel hyaluronan receptor that mediates tumor cell motility. J Cell Biol. 1992;117(6):1343-50

56. Masellis-Smith A, Belch AR, Mant MJ, Turley EA, Pilarski LM. Hyaluronan-dependent motility of B cells and leukemic plasma cells in blood, but not of bone marrow plasma cells, in multiple myeloma: alternate use of receptor for hyaluronan-mediated motility (RHAMM) and CD44. Blood. 1996;87(5):1891-9.

57. Murakami S, Miyake K, June CH, Kincade PW, Hodes RJ. IL-5 induces a Pgp-1 (CD44) bright B cell subpopulation that is highly enriched in proliferative and Ig secretory activity and binds to hyaluronate. J Immunol. 1990;145(11):3618-27.

58. Bourguignon LY, Lokeshwar VB, Chen X, Kerrick WG. Hyaluronic acid-induced lymphocyte signal transduction and HA receptor (GP85/CD44) - cytoskeleton interaction. J Immunol. 1993;151 (12):6634-44.

59. Legras S, Levesque JP, Charrad R, et al. CD44-mediated adhesiveness of human hematopoietic progenitors to hyaluronan is modulated by cytokines. Blood. 1997;89(6):1905-14.

60. Laurent TC, Fraser JR, Pertoft H, Smedsrød B. Binding of hyaluronate and chondroitin sulphate to liver endothelial cells. Biochem J. 1986;234(3):653-8.

61. Engström-Laurent A, Laurent UB, Lilja K, Laurent TC. Concentration of sodium hyaluronate in serum. Scand J Clin Lab Invest. 1985;45(6):497-504.

62. Jeronimo SM, Sales AO, Fernandes MZ, et al. Glycosaminoglycan structure and content differ according to the origins of human tumors. Braz J Med Biol Res. 1994;27(9):2253-8.

63. Martins JR, Passerotti CC, Maciel RM, Sampaio LO, Dietrich CP, Nader HB. Practical determination of hyaluronan by a new noncompetitive fluorescence-based assay on serum of normal and cirrhotic patients. Anal Biochem. 2003;319(1):65-72.
64. Martins JR, Furlanetto RP, Oliveira LM, et al. Comparison of practical methods for urinary glycosaminoglycans and serum hyaluronan with clinical activity scores in patients with Graves' ophthalmopathy. Clin Endocrinol (Oxf). 2004;60(6):726-33.

65. West DC, Hampson IN, Arnold F, Kumar S. Angiogenesis induced by degradation products of hyaluronic acid. Science. 1985;228 (4705):1324-6.

66. Dempsey LA, Brunn GJ, Platt JL. Heparanase, a potential regulator of cell-matrix interactions. Trends Biochem Sci. 2000; 25(8):349-51

67. Freeman C, Parish CR. A rapid quantitative assay for the detection of mammalian heparanase activity. Biochem J. 1997;325 (Pt 1):229-37.

68. Freeman C, Parish CR. Human platelet heparanase: purification, characterization and catalytic activity. Biochem J. 1998;330 (Pt 3): $1341-50$

69. Nicolson GL, Nakajima M, Wakabayashi H, Boyd DD, Diaz D, Irimura $\mathrm{T}$. Cancer cell heparanase activity associated with invasion and metastasis. Adv Enzyme Regul. 1998;38:19-32.

70. Klein U, Von Figura K. Partial purification and characterization of heparan sulfate specific endoglucuronidase. Biochem Biophys Res Commun. 1976;73(3):569-76.

71. Toyoshima M, Nakajima M. Human heparanase. Purification, characterization, cloning, and expression. J Biol Chem. 1999; 274(34):24153-60

72. Vlodavsky I, Goldshmidt O, Zcharia E, Atzmon R, Rangini-Guatta $\mathrm{Z}$, Elkin M, et al. Mammalian heparanase: involvement in cancer metastasis, angiogenesis and normal development. Semin Cancer Biol. 2002;12(2):121-9.

73. Gingis-Velitski S, Zetser A, Flugelman MY, Vlodavsky I, Ilan N. Heparanase induces endothelial cell migration via protein kinase B/Akt activation. J Biol Chem. 2004;279(22):23536-41.

74. Cohen IR, Murdoch AD, Naso MF, Marchetti D, Berd D, Iozzo RV. Abnormal expression of perlecan proteoglycan in metastatic melanomas. Cancer Res. 1994;54(22):5771-4.

75. Reiland J, Sanderson RD, Waguespack M, et al. Heparanase degrades syndecan-1 and perlecan heparan sulfate: functional implications for tumor cell invasion. J Biol Chem. 2004; 279 (9):8047-55.

76. Staquicini FI, Moreira CR, Nascimento FD, et al. Enzyme and integrin expression by high and low metastatic melanoma cell lines. Melanoma Res. 2003;13(1):11-8.

77. Vlodavsky I, Korner G, Ishai-Michaeli R, Bashkin P, Bar-Shavit R, Fuks Z. Extracellular matrix-resident growth factors and enzymes: possible involvement in tumor metastasis and angiogenesis. Cancer Metastasis Rev. 1990;9(3):203-26.

78. Maxhimer JB, Quiros RM, Stewart R, et al. Heparanase-1 expression is associated with the metastatic potential of breast cancer. Surgery. 2002;132(2):326-33.

79. Maxhimer JB, Somenek M, Rao G, et al. Heparanase-1 gene expression and regulation by high glucose in renal epithelial cells: a potential role in the pathogenesis of proteinuria in diabetic patients. Diabetes. 2005;54(7):2172-8.

80. Vlodavsky I, Friedmann Y. Molecular properties and involvement of heparanase in cancer metastasis and angiogenesis. J Clin Invest. 2001;108(3):341-7.

81. Vlodavsky I, Goldshmidt O, Zcharia E, et al. Mammalian heparanase: involvement in cancer metastasis, angiogenesis and nd normal development. Semin Cancer Biol. 2002;12:121-9.

82. Haimov-Kochman R, Friedmann Y, Prus D, et al. Localization of heparanase in normal and pathological human placenta. Mol Hum Reprod. 2002;8(6):566-73.

83. Bitan M, Polliack A, Zecchina G, et al. Heparanase expression in 
human leukemias is restricted to acute myeloid leukemias. Exp Hematol. 2002;30(1):34-41.

84. Eshel R, Ben-Zaken O, Vainas $\mathrm{O}$, et al. Leukomogenic factors downregulate heparanase expression in acute myeloid leukemia cells. Biochem Biophys Res Commun. 2005;335(4):1115-22.

85. Kelly T, Miao HQ, Yang Y, et al. High heparanase activity in multiple myeloma is associated with elevated microvessel density. Cancer Res. 2003;63(24):8749-56.

86. Dhodapkar MV, Kelly T, Theus A, Athota AB, Barlogie B, Sanderson RD. Elevated levels of shed syndecan-1 correlate with tumour mass and decreased matrix metalloproteinase- 9 activity in the serum of patients with multiple myeloma. Br J Haematol. 1997; 99(2):368-71.

87. Klein B, Li XY, Lu ZY, et al. Activation molecules on human myeloma cells. Curr Top Microbiol Immunol. 1999;246:335-41.

88. Seidel C, Sundan A, Hjorth M, et al. Serum syndecan-1: a new independent prognostic marker in multiple myeloma. Blood. 2000; 95(2):388-92.

89. Sanderson RD, Yang Y, Kelly T, MacLeod V, Dai Y, Theus A. Enzymatic remodeling of heparan sulfate proteoglycans within the tumor microenvironment: growth regulation and the prospect of new cancer therapies. J Cell Biochem. 2005;96(5):897-905.

90. Mahtouk K, Hose D, Raynaud P, et al. Heparanase influences expression and shedding of syndecan-1, and its expression by the bone marrow environment is a bad prognostic factor in multiple myeloma. Blood. 2007;109(11):4914-23.

91. Boyd DD, Nakajima M. Involvement of heparanase in tumor metastases: a new target in cancer therapy? J Natl Cancer Inst. 2004;96(16):1194-5

92. Hulett MD, Freeman C, Hamdorf BJ, Baker RT, Harris MJ, Parish CR. Cloning of mammalian heparanase, an important enzyme in tumor invasion and metastasis. Nature Medicine. 1999;5(7):803-9.

93. Simizu S, Ishida K, Osada H. Heparanase as a molecular target of cancer chemotherapy. Cancer Sci. 2004;95(7):553-8.

94. Barrett AJ, Kirschke H. Cathepsin B, Cathepsin H, and cathepsin L. Methods Enzymol. 1981;80 Pt C:535-61.

95. Nägler DK, Storer AC, Portaro FC, Carmona E, Juliano L, Ménard R. Major increase in endopeptidase activity of human cathepsin B upon removal of occluding loop contacts.Biochemistry. 1997; 36(41):12608-15

96. Buck MR, Karustis DG, Day NA, Honn KV, Sloane BF. Degradation of extracellular-matrix proteins by human cathepsin B from normal and tumour tissues. Biochem J. 1992;282 ( Pt 1):273-8.

97. Mort JS, Recklies AD. Interrelationship of active and latent secreted human cathepsin B precursors. Biochem J. 1986 Jan $1 ; 233(1): 57-63$.

98. Linebaugh BE, Sameni M, Day NA, Sloane BF, Keppler D. Exocytosis of active cathepsin B enzyme activity at $\mathrm{pH} 7.0$, inhibition and molecular mass. Eur J Biochem. 1999;264(1):100-9.

99. Ermolieff J, Boudier C, Laine A, Meyer B, Bieth JG. Heparin protects cathepsin $\mathrm{G}$ against inhibition by protein proteinase inhibitors. J Biol Chem. 1994;269(47):29502-8.

100. Fath MA, Wu X, Hileman RE, et al. Interaction of secretory leukocyte protease inhibitor with heparin inhibits proteases involved in asthma. Biol Chem. 1998;273(22):13563-9.

101. Almeida PC, Nantes IL, Chagas JR, et al. Cathepsin B activity regulation. Heparin-like glycosaminogylcans protect human cathepsin $\mathrm{B}$ from alkaline $\mathrm{pH}$-induced inactivation. J Biol Chem. 2001;276(2):944-51.

102. Weiss RE, Liu BC, Ahlering T, Dubeau L, Droller MJ. Mechanisms of human bladder tumor invasion: role of protease cathepsin B. J Urol. 1990;144(3):798-804.
103. Rozhin J, Sameni M, Ziegler G, Sloane BF. Pericellular pH affects distribution and secretion of cathepsin B in malignant cells. Cancer Res. 1994;54(24):6517-25

104. Sloane BF, Moin K, Sameni M, Tait LR, Rozhin J, Ziegler G. Membrane association of cathepsin B can be induced by transfection of human breast epithelial cells with c-Ha-ras oncogene. J Cell Sci. 1994;107 ( Pt 2):373-84.

105. Berquin IM, Sloane BF. Cathepsin B expression in human tumors. Adv Exp Med Biol. 1996;389:281-94.

106. Sloane BF, Rozhin J, Johnson K, Taylor H, Crissman JD, Honn KV. Cathepsin B: association with plasma membrane in metastatic tumors. Proc Natl Acad Sci U S A. 1986;83(8):2483-7.

107. Kos J, Lah TT. Cysteine proteinases and their endogenous inhibitors: target proteins for prognosis, diagnosis and therapy in cancer (review). Oncol Rep. 1998;5(6):1349-61.

108. Cirman T, Oresic K, Mazovec GD, et al. Selective disruption of lysosomes in HeLa cells triggers apoptosis mediated by cleavage of Bid by multiple papain-like lysosomal cathepsins. J Biol Chem. 2004 Jan 30;279(5):3578-87

109. Visscher DW, Sloane BF, Sameni M, Babiarz JW, Jacobson J, Crissman JD. Clinicopathologic significance of cathepsin B immunostaining in transitional neoplasia. Mod Pathol. 1994;7(1):76-81.

110. Khan A, Krishna M, Baker SP, Banner BF. Cathepsin B and tumorassociated laminin expression in the progression of colorectal adenoma to carcinoma. Mod Pathol. 1998;11(8):704-8.

111. Sukoh N, Abe S, Ogura S, et al. Immunohistochemical study of cathepsin B. Prognostic significance in human lung cancer. Cancer. 1994;74(1):46-51.

112. Crocker J, Burnett D, Jones EL. Immunohistochemical demonstration of cathepsin $\mathrm{B}$ in the macrophages of benign and malignant lymphoid tissues. J Pathol. 1984;142(1):87-94.

113. Giraldi T, Sava G, Zorzet S, Perissin L, Piccini P. Activity and inhibition by cytotoxic and antimetastatic drugs of cathepsin Blike cysteine proteinase in transplantable leukemias in mice. Anticancer Res. 1987;7(3 Pt B):343-6.

114. Barbosa CM, Oliveira CR, Nascimento FD, et al. Biphosphinic palladacycle complex mediates lysosomal-membrane permeabilization and cell death in K562 leukaemia cells. Eur J Pharmacol. 2006;542(1-3):37-47.

115. Tsukahara T, Ishiura S, Kominami E, Sugita H. Changes in proteinase activities during the differentiation of murine erythroleukemia cells. Exp Cell Res. 1990;188(1):111-6.

116. Ward CJ, Crocker J, Chan SJ, Stockley RA, Burnett D. Changes in the expression of elastase and cathepsin $\mathrm{B}$ with differentiation of U937 promonocytes by GMCSF. Biochem Biophys Res Commun. 1990;167(2):659-64.

117. Lokshina LA, Bylinkina VS, Samoilova RS, Gureeva TA, Golubeva NV, Polianskaia AM. [Proteolytic enzymes in human lymphocytic leukemia cells. I. Activity of dipeptidylaminopeptidase IV, plasminogen activator and cathepsins B and L in cells with different immunologic phenotype]. Biokhimiia. 1993;58(7):1104-15.

Avaliação: Editor e dois revisores externos

Conflito de interesse: não declarado

Recebido: 10/07/2007

Aceito após modificações: 22/02/2008 